\title{
A Pós-graduação no IMIP: 20 anos
}

A formação de recursos humanos para a saúde com elevado nível de conhecimento teórico, habilidades e atitudes éticas, adequados à realidade local, sempre foi uma das preocupações para o Prof. Fernando Figueira, desde quando criou o Instituto de Medicina Integral Prof. Fernando Figueira (IMIP) em 1960. O seu sonho era construir uma escola modelo de graduação na área da saúde, sediada no IMIP, que pudesse atender às necessidades de saúde das populações locais, em especial as daquelas mais carentes, além de que esse modelo pudesse também ser replicado em locais com realidades semelhantes. Esse sonho, que chegou a ser concretizado por seus discípulos na década passada com a criação da Faculdade Pernambucana de Saúde (FPS), passou por várias etapas antes de ser materializado.

O IMIP abrigou desde a sua criação a disciplina de pediatria das duas escolas médicas do Estado de Pernambuco - a Universidade Federal de Pernambuco (UFPE) e a Universidade de Pernambuco (UPE) - das quais o Prof. Fernando Figueira foi o titular dessa especialidade. Por sua iniciativa também teve início no IMIP, o primeiro programa de residência médica em pediatria nas regiões norte e nordeste do Brasil. Mantendo essa vocação para o ensino e já com o pleno funcionamento dos programas de pediatria para alunos do $4^{\circ}$ e $6^{\circ}$ anos do curso médico e da residência médica, no ano de 1973, o Instituto passou a sediar, juntamente com a UFPE, o primeiro curso de mestrado em pediatria. Esse curso funcionou do IMIP até o ano de 1983 quando foi transferido para a UFPE.

A configuração da escola de graduação em saúde, tão sonhada pelo Prof. Fernando Figueira, começou a se materializar no final da década de 1980, a partir da troca de idéias com seu grande amigo, o Prof. G. J. Ebrahim, responsável pelo curso de mestrado do "Institute of Child Health at London University". O Prof. Fernando Figueira seguiu a idéia do Prof. G. J. Ebrahim de inicialmente investir na formação de um corpo docente de excelente qualidade, para posteriormente criar a sua escola de graduação na área da saúde. Alguns professores assistentes do IMIP já haviam realizado pós-graduação no serviço do Prof. Ebrahim enquanto outros foram encaminhados para reforçar esse corpo docente. Em 1993, contando com a colaboração dos professores Malaquias Batista Filho e Bertoldo Kruse na elaboração do projeto do curso, prontamente aprovado pela CAPES, teve início o programa de pós-graduação em saúde materno-infantil do IMIP, o primeiro então na América Latina, seguindo o modelo acadêmico da "London School of Hygiene and Tropical Medicine".

Nesse modelo desenvolvido pelo IMIP, a meta estabelecida de cursos de graduação de excelente qualidade, seria plenamente alcançada com a formação do corpo de docentes para cada programa dos cursos. O curso de pós-graduação foi criado, portanto, com o objetivo, a princípio, de formar mestres e doutores para melhor assistirem aos seus alunos de graduação. Conforme esse modelo, a formação do pós-graduando ultrapassa os limites de um simples pesquisador para um docente-pesquisador, mantendo estreito o vínculo da pós-graduação com a graduação. Essa preocupação com o ensino tem se mantido ao longo desses 20 anos, tanto que o IMIP foi o primeiro programa de pós-graduação na área de saúde a utilizar a metodologia de aprendizado baseado em problemas nos seus cursos de mestrado e doutorado. Em 2008, com a implantação desse novo currículo, tendo como eixo norteador o planejamento, o desenvolvimento e a transmissão da pesquisa, o programa visou à formação de docentes com um melhor preparo em modelos pedagógicos ativos e uma maior competência para a produção de artigos científicos.

Obviamente, a formação dos docentes não poderia se restringir aos programas de graduação do IMIP. Nesses 20 anos, o seu programa formou 216 mestres e doutores, muitos dos quais oriundos de outros estados do Brasil e hoje inseridos em suas devidas regiões no ensino, pesquisa, assistência e gestão no campo da atenção à criança e à mulher. Dessa forma, o programa de pós-graduação do IMIP tem contribuído para a formação de re- 
cursos humanos de excelência para o ensino, pesquisa e gestão na Região Nordeste do Brasil.

Finalmente não podemos esquecer que, caminhando lado a lado, com os objetivos de desenvolvimento acadêmico e científico da Instituição, nela foram criados e patrocinados os periódicos Revista do IMIP (1986-2000) e Revista Brasileira de Saúde Materno Infantil (RBSMI) (2001 - atual), ambas com marcante presença na divulgação de trabalhos relevantes para as comunidades médica e de saúde coletiva. Cabe lembrar assim que a Revista do IMIP teve a oportunidade de publicar o relato do primeiro caso de AIDS em Pernambuco e sétimo no Brasil enquanto a RBSMI, que é indexada em 13 bases bibliográficas internacionais, integrou em 2007, a convite do Council of Science Editors, O Global Theme Issue on Poverty and Human Development, com a publicação de cinco artigos, sendo dois de autores do próprio IMIP e três de autores internacionais.

Essas realizações são importantes, mas são apenas algumas das provenientes do grande mestre Prof. Fernando Figueira.

\section{João Guilherme Bezerra Alves 1}

1 Coordenador do Programa de Pós-graduação em Saúde Materno-Infantil. Instituto de Medicina Integral Prof. Fernando Figueira. Rua dos Coelhos, 300. Boa Vista. Recife, PE, Brasil. CEP: 50.070-550 